\title{
A literatura no ensino médio segundo a abordagem do PNLD 2015: entre a tradição e a transformação
}

\author{
Literature in high school in the 2015 PNLD approach: between \\ tradition and transformation
}

Luiz Antônio Ribeiro, Doutor em Letras e Linguística, Cefet-MG, luiz.antonio.ribeiro32@gmail.com

Cláudia Mara de Souza, Doutora em Estudos Linguísticos, Cefet-MG, smclaudia@hotmail.com

\section{Resumo}

Fundamentando-se em referenciais teóricos relacionados ao letramento literário, esta pesquisa pretende investigar sobre ensino de literatura no PNLD 2015 e nas coletâneas do Guia dos livros didáticos do Ensino Médio. Algumas considerações sinalizam uma abordagem tradicional de ensino e convidam à reflexão sobre a formação para o letramento literário.

Palavras chave: PNLD; Letramento literário; Ensino de literatura

\begin{abstract}
Based on theoretical frameworks for literary literacy, this research aims to investigate literature teaching in the 2015 PNLD and in the collection of the Guide to high school textbooks. Some of the considerations indicate that the teaching approach is a traditional one, and they encourage reflection on literary literacy development.
\end{abstract}

Key words: PNLD, literacy, literary teaching 


\section{V SILIDIV SIMAR}

PUC-Rio - Dias 28, 29 e 30 de julho de 2015

\section{Considerações iniciais}

Este trabalho propõe-se a avaliar o tratamento dado ao ensino de literatura no PNLD 2015 e nas coletâneas constantes do Guia do PNLD 2015. A pergunta-chave que norteia esta pesquisa é: Qual o tratamento dado ao ensino de literatura no PNLD 2015 e nas coletâneas constantes do Guia dos livros didáticos do PNLD 2015? A hipótese é que esses documentos sinalizam a formação para o letramento literário, mas nem sempre oferecem subsídios para que ela aconteça e, na maioria das vezes, favorecem uma perspectiva de ensino tradicional de literatura. Esta pesquisa se desenvolveu em três seções: Literatura e formação do leitor literário; a formação do leitor literário segundo os documentos oficiais; e a literatura no Ensino Médio: o que propõem o PNLD 2015 e os compêndios e manuais didáticos.

\section{Literatura e formação do leitor literário}

Nesta seção, refletimos sobre o que é literatura e seu caráter humanizador. Apresentamos também uma concepção de letramento literário e destacamos sua importância para o ensino.

\subsection{Literatura e dialogismo}

Quando nos propomos a refletir sobre a formação do leitor literário no Ensino Médio, questionamos: que leitor queremos formar? Segundo Uchôa (1991, p. 76), leitor é "aquele que, lendo um texto, é capaz de discutir ideias, expor interpretações individuais e partilhar das experiências geradas pela incursão nos textos, em suma, alcançar o adentramento crítico da leitura feita." Esse processo de formação contribui para a autonomia dos leitores, proporcionando-lhes condições de selecionar obras, clássicas ou não, para ampliação do repertório de leituras.

Esse objetivo exige também uma reflexão sobre qual concepção de linguagem deverá nortear nossa prática. Os documentos oficiais, dentre eles as Orientações Curriculares para o Ensino Médio: Linguagens, Códigos e suas Tecnologias (2006), ressaltam que 0 ensino de língua deve se fundamentar numa visão sociointeracionista da linguagem, segundo a qual a enunciação resulta da interação entre indivíduos socialmente organizados. Bakhtin (1986) concebe o dialogismo como um elemento constitutivo da própria linguagem, tendo em vista que "toda palavra comporta duas faces. Ela é determinada, tanto pelo fato de que procede de alguém, como pelo fato de que se dirige a alguém. Ela constitui justamente o produto da interação do locutor e do ouvinte" (p. 113) e resulta da interseção de vários planos textuais, dentre eles: o escritor, o leitor, bem como o contexto cultural e histórico em que se processa o ato da leitura.

Essa concepção de dialogismo encontra ressonância na seguinte afirmação do crítico literário Antônio Cândido acerca do papel da literatura: 


\section{V SILIDIIV SIMAR \\ PUC-Rio - Dias 28, 29 e 30 de julho de 2015}

Ao confirmar e negar, propor e denunciar, apoiar e combater, a literatura possibilita ao homem viver seus problemas de forma dialética, tornando-se um "bem incompressível", pois confirma o homem na sua humanidade, inclusive porque atua em grande parte no subconsciente e no inconsciente. (CÂNDIDO, 1995, p. 243).

Esse mesmo autor assim define literatura:

Chamarei de literatura, de maneira mais ampla possível, todas as criações de toque poético, ficcional ou dramático, em todos os níveis de uma sociedade, em todos os tipos de cultura, desde o que chamamos folclore, lenda, até as formas mais complexas e difíceis de produção das grandes civilizações. (CÂNDIDO, 1995, p. 242).

A teoria estética da recepção ressalta que o texto literário possui função diferenciada dos demais textos que circulam ordinariamente em nossa sociedade. Nos dizeres de Cosson (2007, p. 17), "a literatura é uma experiência a ser realizada". O significado gerado a partir do encontro dos sujeitos - escritor e leitor será sempre polissêmico e mutável. Para que a literatura cumpra esse papel, tornase imperativa a reflexão e a promoção do letramento literário, conforme discutiremos a seguir.

\subsection{A formação do leitor na perspectiva do letramento literário}

A tradição escolar privilegia o estudo da história da literatura, com ênfase nas escolas e na cronologia literárias, bem como nos dados biográficos dos autores; selecionou a leitura de textos clássicos como forma de humanização sob o argumento de que esse tipo de literatura é considerado universal. Assim, o ensino de literatura objetiva instrumentalizar o aluno para identificar determinadas obras e autores como pertencentes a uma escola literária, bem como o contexto históricocultural em que elas se encontram.

Entretanto, considerando-se que a literatura é uma capacidade transformadora do ser, é primordial refletir sobre o seu conceito, valor e função social. Nessa vertente, ganha expressão a prática pedagógica com foco no letramento literário, definido por Buzato (2007, apud Rojo, 2009, p. 101) como "práticas sociais, plurais e situadas, que combinam oralidade e escrita de formas diferentes em eventos de natureza diferente, e cujos efeitos ou consequências são condicionados pelo tipo de prática e pelas finalidades específicas a que se destinam".

O letramento literário resulta de um conjunto de estratégias que favorecem o desenvolvimento da educação literária com vistas à formação leitora dos alunos, conforme propõe Paulino: 


\title{
D V SILIDIV SIMAR
}

PUC-Rio - Dias 28, 29 e 30 de julho de 2015

\begin{abstract}
A formação de um leitor literário significa a formação de um leitor que saiba escolher suas leituras, que aprecie construções e significações verbais de cunho artístico, que faça disso parte de seus afazeres e prazeres. Esse leitor tem de saber usar estratégias de leitura adequadas aos textos literários, aceitando o pacto ficcional proposto, com reconhecimento de marcas linguísticas de subjetividade, intertextualidade, interdiscursividade, recuperando a criação de linguagem realizada, em aspectos fonológicos, sintáticos, semânticos e situando adequadamente o texto em seu momento histórico de produção (PAULINO, 2004, p.56).
\end{abstract}

Essa concepção de letramento ultrapassa o âmbito do contexto escolar e abarca outras esferas sociais, de modo a valorizar e fortalecer as ações dos diferentes agentes, o resgate da sua autoestima e a construção de uma identidade forte. Considera a prática dos letramentos multiculturais ou multiletramentos, conforme Rojo (2009), que incluem os produtos culturais letrados valorizados tanto pela esfera escolar e pela classe dominante quanto por diferentes culturas locais e populares, além dos produtos da cultura de massa. Compreende-se, desse modo, o ensino de literatura para além dos domínios específicos do texto, abrangendo a sua esfera de circulação social.

\section{A formação do leitor literário segundo os documentos oficiais}

Nesta seção, buscamos identificar as perspectivas para o trabalho com o texto literário no Ensino Médio a partir do que propõem os documentos oficiais. Para isso, pautamo-nos nos Parâmetros Curriculares Nacionais para o Ensino Médio (PCNEM), nas Orientações Curriculares Nacionais para o Ensino Médio (OCNEM) e no guia do PNLD/2015.

\subsection{Formação literária no Ensino Médio de acordo com os PCNEM e as OCEM}

Os PCNEM procuraram incorporar o ensino de literatura na perspectiva da linguagem e consideram que dados, informações, ideias e teorias não podem ser isolados de suas condições de produção, do tipo de sociedade em que são gerados e recebidos, de sua relação com outros conhecimentos:

O trabalho do professor centra-se no objetivo de desenvolvimento e sistematização da linguagem interiorizada pelo aluno, incentivando a verbalização da mesma e o domínio de outras utilizadas em diferentes esferas sociais. Os conteúdos tradicionais de ensino de língua, ou seja, nomenclatura gramatical e história da literatura são deslocados para um segundo plano. O estudo da gramática passa a ser uma estratégia para compreensão/interpretação/produção de textos e a literatura integra-se à área de leitura (BRASIL, 2000). 


\section{V SILIDIV SIMAR}

PUC-Rio - Dias 28, 29 e 30 de julho de 2015

O trabalho com a literatura integra-se ao da leitura e ao dos gêneros discursivos. Contudo, os PCNEM não apresentam uma metodologia mais precisa de como efetivá-lo. No intuito de acrescentar algumas discussões que não foram contempladas pelos PCNEM, foram publicados os PCN+. Segundo esse documento

A Literatura, particularmente, além de sua específica constituição estética, é um campo riquíssimo para investigações históricas realizadas pelos estudantes, estimulados e orientados pelo professor, permitindo reencontrar o mundo sob a ótica do escritor de cada época e contexto cultural. Camões ou Machado de Assis; Cervantes ou Borges; Shakespeare ou Allan Poe; Goethe ou Thomas Mann; Dante ou Guareschi; Molière ou Sthendal (BRASIL, 2002, p.19).

Essa abordagem parece-nos problemática, pois, se até determinado período, a literatura foi usada como pretexto para ensinar gramática, nesse documento há um apontamento para a investigação histórica. O estatuto estético da literatura é mencionado, mas não é discutido no mesmo. Contudo, a mudança da literatura para a área de leitura, considerando-se a formação de um aluno leitor, pode ser encarada de forma positiva.

Nos documentos oficiais, não se identificam o conceito de literatura e critérios que sirvam de suporte para caracterizar o "texto literário como forma peculiar de representação e estilo em que predominam a força criativa da imaginação e a intenção estética", como se afirma nos Parâmetros Curriculares do Ensino Fundamental (BRASIL, 2002).

Já as OCEM avançam com a proposta apresentada nos PCN e partem para a apropriação do conceito de Letramento. Reforçam a ideia de não se ensinar literatura pelo viés da história da literatura e sugerem a experiência significativa e plena com o texto literário. Assim,

Para cumprir com esses objetivos, entretanto, não se deve sobrecarregar o aluno com informações sobre épocas, estilos, características de escolas literárias, etc., como até hoje tem ocorrido, apesar de os PCN, principalmente o $\mathrm{PCN}+$, alertarem para o caráter secundário de tais conteúdos... podemos pensar em letramento literário como estado ou condição de quem não apenas é capaz de ler poesia ou drama, mas dele se apropria efetivamente por meio da experiência estética, fruindo-o (BRASIL, 2006, p.54$55)$.

Na concepção deste documento, a experiência literária é entendida como o contato efetivo com o texto. O prazer estético é compreendido como conhecimento, participação, fruição, o que, evidentemente, não pode ser obtido pelo estudo da história da literatura, pela memorização de conceitos, datas, lista de autores. 


\section{V SILIDIV SIMAR}

PUC-Rio - Dias 28, 29 e 30 de julho de 2015

\subsection{Formação literária no Ensino Médio de acordo com o PNLD}

De acordo com o Guia PNLD 2015, há duas tendências metodológicas que se evidenciam na tensão da formação do leitor de textos literários: uma prevê a literatura como um eixo de ensino próprio; e outra, como um objeto de conhecimento particular, construído pela articulação da leitura de textos considerados literários como uma reflexão específica (BRASIL, 2014, p.23).

Na primeira opção, observamos que o tratamento dispensado ao ensino de literatura é mais tradicional, aparece em seção distinta no LD ou em capítulo específico. Além disso, "na maioria das vezes, a exposição da matéria segue uma sucessão cronológica de períodos, escolas, tendências e estilos de época" (BRASIL, 2014 , p.21). Neste caso, o trabalho apresenta uma série de informações, listas de textos e autores representativos e explora pouco o trabalho com a leitura das obras propriamente dita.

Na segunda opção, o ensino de literatura é viabilizado pela leitura de textos da área, de certos gêneros e autores representativos. Dá-se ênfase ao caráter ficcional e estético dos textos, explorando-se a compreensão, o estilo e o tema. Assim, o foco é a formação do leitor. De acordo com o Guia, para que não se percam os conhecimentos históricos e teóricos, algumas coleções apostam em seções e apêndices para sistematização de tais informações. Ou seja, apesar de se propor um estudo pelos gêneros, a historiografia precisa ser sistematizada de alguma forma.

\section{A literatura no Ensino Médio: o que propõem o PNLD 2015, os compêndios e manuais didáticos}

Nesta seção, propomos uma análise do referencial teórico apresentado no Guia e da resenha de uma das coleções; fundamentamos nossa argumentação com conteúdos curriculares apresentados em uma coleção proposta no Guia; e, por fim, analisamos um capítulo de um manual didático, visando à demonstração qualitativa da abordagem. A coleção analisada foi a segunda edição da obra "Português: contexto, interlocução e sentido", de autoria de Maria Luiza M. Abaurre, Maria Bernadete M. Abaurre e Marcela Pontara, publicada pela Editora Moderna em 2013. A seleção de tal obra se deve ao fato de esta ter sido adotada em 2014 na escola em que atuamos como professor e da possibilidade de ser adotada novamente para o ano letivo de 2015.

3.1. Análise do Guia PNLD 2015: objetivo e concepções sobre o ensino de literatura

O objetivo do PNLD 2015 é colaborar para que as escolas promovam uma escolha qualificada do livro didático a partir de um processo de discussão amplo e criterioso. O Guia destaca a importância da manutenção da disciplina Língua Portuguesa no 


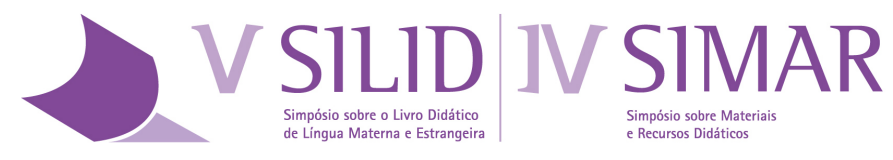

PUC-Rio - Dias 28, 29 e 30 de julho de 2015

Ensino Médio e ressalta a relevância cultural da literatura, em especial da literatura brasileira na cultura e na vida social do país.

Dezessete coleções passaram pelo crivo de avaliação do PNLD 2015, das quais dez foram aprovadas. Estas atendem os objetivos oficiais estabelecidos para cada um dos quatro grandes objetos de ensino de língua portuguesa - leitura, produção de textos escritos, oralidade e conhecimentos linguísticos. O PNLD 2015 afirma ter adotado a perspectiva das OCEM (2006) como princípios e critérios de avaliação dos livros didáticos. As resenhas das coleções destacam a literatura como um eixo desvinculado dos demais propostos pelas OCEM (2006), mas o PNLD 2015 ressalta que "seus comentários sempre dizem respeito à formação do leitor e à construção de conhecimentos linguísticos e históricos próprios dessa esfera" (p. 18).

Diferentemente do que propõem as OCEM (2006), a coleção em análise segue um modelo teórico-metodológico tradicional e se organiza em torno do eixo Literatura - Gramática e Produção de Texto. O estudo da literatura é explorado como um eixo autônomo, contemplado nas três primeiras unidades dos livros, constituídas de onze capítulos nos dois primeiros volumes e de oito no terceiro, que conta também com uma seção especial dedicada aos estudos da literatura africana.

Quanto à organização temática do conteúdo de literatura, a coleção apresenta, no volume 1, uma introdução aos estudos literários. Os autores propõem um estudo metalinguístico da literatura, situando-a no campo da arte, explorando-a enquanto linguagem, configurando os gêneros literários e adotando uma perspectiva historiográfica, sob o argumento de que a literatura é a expressão de uma época. A partir daí, ainda no volume 1 e nos demais volumes, a coleção contempla o estudo das escolas literárias, desde a Idade Média até as tendências contemporâneas. Na seção dedicada à literatura africana, propõe-se um estudo literário da poesia e da prosa africana, bem como de seus principais autores.

A proposta pedagógica centra-se principalmente na exposição teórica do conteúdo, seguida de uma breve análise textual, que servirá de suporte para o estudo do texto. Tal estudo fundamenta-se na interpretação do texto, na exploração de elementos linguísticos e literários, na identificação das características do estilo de época, nas concepções de mundo do escritor e/ou personagens, bem como na exploração do contexto histórico. Não se abre espaço para a promoção do diálogo entre o texto literário em estudo com outras obras. Para preencher essa lacuna, cada capítulo é finalizado com um tópico intitulado "Interações", que propõe, superficialmente, uma interface entre o estilo estudado e outros estilos de época, outras manifestações artísticas e/ou outros gêneros do discurso.

Em todos os capítulos, há um tópico intitulado "Os agentes do discurso", em que são abordadas as condições de produção do texto/discurso. Entretanto, essas condições de produção, a relação entre os interactantes do discurso, as representações sociais, a polifonia, a construção da argumentação, etc. não são exploradas a partir de textos. 


\section{V SILIDIV SIMAR \\ PUC-Rio - Dias 28, 29 e 30 de julho de 2015}

No plano estrutural, principalmente em relação ao estudo dos estilos de época, a coleção apresenta um modelo padrão de organização. Os capítulos são introduzidos com os objetivos, a leitura de uma imagem e a análise de um texto. Em seguida, apresenta-se o contexto sócio-histórico, político e cultural, bem como uma introdução do estilo de época a ser estudado. Logo após, são explorados aspectos relativos à escola literária em Portugal e no Brasil, tais como características do estilo e principais autores. Esse referencial teórico vem intercalado com análise e com propostas de atividades pautadas de excertos de textos de autores vinculados à estética literária em estudo, o que dificulta ao aluno a percepção e compreensão do todo.

Dentre outras críticas apresentadas pelo próprio PNLD 2015 às coleções aprovadas e que também podem ser observadas na obra que estamos analisando, destacam-se: prevalência de autores e gêneros mais consagrados em um estilo de época, sem uma proposta consolidada de diálogo com outros autores e obras que tratem do mesmo tema; pouco espaço reservado à produção literária que não se identifica com os cânones estabelecidos; e pouca exploração de textos midiáticos e multimodais. Problemas como esses dificultam, se não impedem, que o aluno compreenda o que vem a constituir o caráter literário de um texto, os critérios que definem a canonicidade de uma obra literária e a fruição do texto enquanto obra de arte.

\subsection{Um capítulo da obra analisada}

Nesta seção, analisamos um capítulo do volume 3, a fim de verificarmos como se dá na prática a abordagem do eixo de leitura literária.

A obra é densa como toda coleção. Há muita informação, contextualização histórica, características do estilo e sobressai o considerável volume de fragmentos de texto por capítulo. No capítulo 4, como exemplo, "Segunda geração: misticismo e consciência social", assim como nos demais dos volumes, há a apresentação de objetivos para o estudo proposto. Neste caso, são onze, dentre os quais, destacamse:

1. Caracterizar o projeto literário da poesia da segunda geração modernista.

2. Analisar de que modo se articulam os agentes do discurso no período e como essa articulação influenciou o projeto literário da poesia da segunda geração modernista.

3. Reconhecer os aspectos essenciais da poesia de Carlos Drummond de Andrade e identificar os eixos temáticos predominantes na obra do autor (ABAURRE, M.L.M. ;ABAURRE, M.B.;PONTARA, M., 2013, p.75). 


\section{SILID IV SIMAR}

PUC-Rio - Dias 28, 29 e 30 de julho de 2015

O capítulo inicia-se com a leitura de uma imagem, para a qual são propostas algumas perguntas para discussão oral. Em seguida, apresenta-se a subseção "Da imagem para o texto", na qual há um poema para leitura. Segue-se com contextualização histórica do período. As características, o projeto literário, os agentes do discurso, a linguagem são tópicos teoricamente tratados a seguir. Por fim, são destacados os autores representativos do período com leituras de textos, bem como, de fragmentos de textos e algumas atividades de interpretação. $O$ capítulo encerra-se com atividades de interpretação de poemas e imagem, com uma produção de texto e uma notícia na subseção "Interações".

A maior parte dos exercícios de interpretação se encerra em si mesma e nos gêneros explorados. Por exemplo, nas atividades para interpretação de dois poemas, um de Cecília Meireles e outro de Vinicius de Moraes, apesar de estarem dispostos na mesma página (p. 89), e com atividades similares, não se proporciona nenhum diálogo entre os mesmos. Além disso, as questões sobre o texto focam-se nas formas e análise da estrutura e características do gênero. Encontramos questões que focalizam, por exemplo, na exploração da conjunção "porque" e seu sentido no poema, outras na relação de causa/consequência estabelecida entre as informações dos versos, no uso do tempo verbal e sua relação com o poema, na identificação de antíteses e o que simbolizam (questões 2, 3, 4 e 5 p.89). Essas atividades não exploram o contexto, nem os aspectos sociais envolvidos no poema, ou seja, não há questões pertinentes ao letramento literário.

A intertextualidade, a interdiscursividade, os múltiplos letramentos poderiam ser trabalhados de maneira mais explícita e sistemática. No mesmo capítulo, na seção "Interações" (p.93), encontramos a leitura de mais dois poemas "Os pobres" de Murilo Mendes e "Agosto de 1964" de Ferreira Gullar, ambos precedidos por notas curtas destacando algumas características do período como visão mais crítica do eu-lírico e sobre o eu-lírico frente ao mundo. Contudo, não observamos atividades que visassem à correlação entre as leituras ou as interações entre as obras. Chama-nos a atenção o fato de o livro ser destacado no Guia do PNLD como uma obra que pode proporcionar a perspectiva discursiva em vários eixos (BRASIL, 2014, p.29), entretanto, a forma estanque como é proposto o trabalho de interpretação dos textos de leitura literária revela que há muito a se fazer.

\section{Considerações finais}

Neste artigo, buscamos refletir sobre o tratamento dado ao ensino de literatura nos documentos oficiais, no PNLD e nas coletâneas constantes do Guia dos Livros Didáticos do PNLD 2015. Primeiramente abordamos o caráter ficcional, poético e/ou dramático do texto literário. Adotamos a concepção de letramento literário, contemplada nas bases teóricas dos documentos oficiais. Entretanto, esses documentos não explicam satisfatoriamente como ensinar com vistas a tal letramento. Nesses documentos, evidencia-se um tratamento da literatura que 


\section{SILID IV SIMAR}

PUC-Rio - Dias 28, 29 e 30 de julho de 2015

privilegia o estudo das escolas literárias sob um viés histórico, as características de cada estilo, bem como autores e obras literárias consagradas pelo cânone. Há uma limitação do estudo dos aspectos formais, conceituais e estilísticos que vão contribuir para a fruição estética e uma reflexão sobre as condições de produção do discurso. Distancia-se, portanto, do caráter humanizador e libertador da literatura, manifestado pela condição de alteridade e (re)criação da realidade cotidiana.

\section{Referências Bibliográficas}

ABAURRE, M.L.M.; ABAURRE, M.B.; PONTARA, M. Português: contexto, interlocução e sentido. $2^{\mathrm{a}}$ ed. São Paulo: Moderna, 2013.

BAKHTIN, Mikhail. Marxismo e filosofia da linguagem. São Paulo: Hucitec, 1986.

BRASIL. Ministério da Educação. Secretaria de Educação Básica. Orientações Curriculares para o Ensino Médio: Linguagens, códigos e suas tecnologias. Brasília: MEC/SEB, 2006.

BRASIL. Ministério da Educação. Secretaria de educação Básica. Fundo Nacional de Desenvolvimento da Educação. Guia de livros didáticos: PNLD 2015. Língua portuguesa: Ensino Médio. Brasília: MEC/SEB, 2014.

BRASIL. Parâmetros Curriculares Nacionais: Ensino Médio. Brasília: MEC/ Semtec, 2000.

BRASIL. Ministério da Educação. Parâmetros em Ação, Ensino Médio: Linguagens, Códigos e suas Tecnologias / Secretaria de Educação Média e Tecnológica - MEC; SEMTEC, 2001. 340 p.

BRASIL. PCN+ Ensino Médio: orientações educacionais complementares aos Parâmetros Curriculares Nacionais. Vol. Linguagens, códigos e suas tecnologias. Brasília: MEC/ Semtec, 2002.

BRASIL. Edital no 12, de 8 de maio de 2014. Exame Nacional do Ensino Médio ENEM 2014, disponível em http://goo.gl/QkW1FG.

CÂNDIDO, Antônio. Vários escritos: o direito à literatura. 3a ed. São Paulo: Duas Cidades, 1995.

COSSON, Rildo. Letramento literário: teoria e prática. São Paulo: Contexto, 2007. 
PAULINO, Graça. Formação de leitores: a questão dos cânones literários. Revista Portuguesa de Educação, vol. 17, n. 01. Braga, Portugal: Universidade do Minho, 2004.

ROJO, Roxane. Letramentos múltiplos, escola e inclusão social. São Paulo: Parábola Editorial, 2009.

UCHOA, Carlos Eduardo F. A linguística e o ensino de português. In: Cadernos de Letras, n. 2. Niterói: UFF/Instituto de Letras, 1991. 